\title{
Sacral nerve stimulation in patients with ileal pouch-anal anastomosis
}

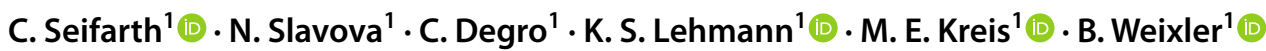

Accepted: 14 June 2021 / Published online: 23 June 2021

(c) The Author(s) 2021

\begin{abstract}
Purpose Functional results after proctocolectomy and ileal pouch-anal anastomosis (IPAA) are generally good. However, some patients suffer from high stool frequency or fecal incontinence. Sacral nerve stimulation (SNS) may represent a therapeutic alternative in these patients, but little is known about indication and results. The aim of this study was to evaluate incontinence after IPAA and demonstrate SNS feasibility in these patients.

Methods This retrospective study includes patients who received a SNS between 1993 and 2020 for increased stool frequency or fecal incontinence after proctocolectomy with IPAA for ulcerative colitis. Proctocolectomy was performed in a two- or three-step approach with ileostomy closure as the last step. Demographic, follow-up data and functional results were obtained from the hospital database.

Results SNS was performed in 23 patients. Median follow-up time after SNS was 6.5 years (min. 4.2-max. 8.8). Two patients were lost to follow-up. The median time from ileostomy closure to SNS implantation was 6 years (min. 0.5-max. 14.5). Continence after SNS improved in 16 patients (69\%) with a median St. Marks score for anal incontinence of 19 (min. 4-max. 22) before SNS compared to 4 (0-10) after SNS placement $(\mathrm{p}=0.012)$. In seven patients, SNS therapy was not successful. Conclusion SNS implantation improves symptoms in over two-thirds of patients suffering from high stool frequency or fecal incontinence after proctocolectomy with IPAA. Awareness of the beneficial effects of SNS should be increased in physicians involved in the management of these patients.
\end{abstract}

Keywords Fecal incontinence $\cdot$ Ulcerative colitis $\cdot$ Sacral nerve stimulation $\cdot$ IPAA $\cdot$ Proctocolectomy

\section{Introduction}

C. Seifarth and N. Slavova contributed equally to this work.

C. Seifarth

claudia.seifarth@charite.de

$\triangle$ N. Slavova

claudia.seifarth@charite.de

C. Degro

claudius.degro@charite.de

K. S. Lehmann

kai.lehmann@charite.de

M. E. Kreis

martin.kreis@charite.de

B. Weixler

benjamin.weixler@charite.de

1 Department of General, Visceral, and Vascular Surgery, Berlin Institute of Health, Charité Universitätsmedizin Berlin, Freie Universität Berlin, Humboldt-Universität Zu Berlin, Berlin, Germany
J-pouch formation with ileal pouch-anal anastomosis (IPAA) is the restorative procedure of choice after proctocolectomy [1]. Functional results after IPAA are usually very good [2-4]. However, fecal incontinence may be a consequence and negatively impact quality of life (QoL) and overall outcome. Fecal incontinence is defined as the inability to control feces or gas. The range of fecal incontinence described after IPAA varies widely and seems to progress over time [3-5]. Daytime stool incontinence is described in 1 to $25 \%$ of patients after J-pouch formation with IPAA [2-7]. Incontinence at night seems to be more common at 8 to $49 \%$ [3-8]. Increased stool frequency is another reported factor that negatively impacts quality of life [9].

The pathogenesis of fecal incontinence after J-pouch reconstruction with IPAA is not fully understood. On the one hand, proctocolectomy with IPAA includes thorough intersphincteric excision and, on the other hand, maximum preservation of the sphincter function. Even so, the 
procedure can affect the upper parts of the internal sphincter and therefore may cause dysfunction, mainly at night [8]. Another possible mechanism could be a delayed function of the puborectalis muscle due to an altered postoperative latency of the sacral nerve [10].

Sacral nerve stimulation (SNS) is an established therapy for fecal incontinence in general or in patients with sphincter defects $[11,12]$ with low perioperative morbidity and good patients' experience $[12,13]$. Recent experience has shown good feasibility and clinical benefit, albeit based primarily on retrospective data $[14,15]$. In addition, SNS seems to be also effective in the treatment of functional deficits after IPAA $[2,16]$. These observations are encouraging but are based on studies with a small number of patients [2]. There is a case report $(n=1)$ [17], a retrospective study $(n=7)$ [18], and a cohort study $(n=4)$ [16] working on SNS for IPAA. We, therefore, analyzed our experience from over 20 years of IPAA surgery and SNS. With this study, we aimed to evaluate the effectiveness and usefulness of SNS therapy for the treatment of fecal incontinence according to IPAA.

\section{Methods}

\section{Patients}

This is a retrospective single-center, single-cohort outcome study evaluating the effect of SNS in patients with high stool frequency or fecal incontinence after proctocolectomy with J-pouch reconstruction and IPAA. Inclusion period was from January 1993 until December 2020. The analysis included gender, age, time to SNS, digital rectal examination scoring system (DRESS) before and after SNS implantation, St. Marks incontinence score (validated score for fecal incontinence) before and after SNS implantation, fecal incontinence at night, and stool thickening drugs before and after SNS implantation, as well as biofeedback and pelvic floor training as further continence supporting tools before and after SNS implantation.

\section{Interventions}

The indication for SNS implantation in patients with refractory fecal incontinence treatment after IPAA was based on individual decisions and is currently not an established therapeutic method, including in this work. All selected patients initially received a PNE (percutaneous nerve examination) as part of a test phase. Since all patients showed a positive signal to PNE, a temporary stimulating electrode was placed under general anesthesia. Based on clinical standards, prophylactic antibiotics were given prior to the procedure. During electrode insertion, radiological controls of correct placement close to sacral foramen two (S2) or three (S3) and electrophysiological monitoring of contractions of the pelvic floor, the external anal sphincter, and the toe were performed. Optimal electrode position was defined as the best motor response of the pelvic floor/external sphincter muscle with low stimulation amplitude. The PNE line then was attached to the skin. PNE was started 4 to $12 \mathrm{~h}$ after intervention. After hospital discharge and with a successful response and symptom improvement of at least 50\%, the final SNS was implanted. If improvement was less than $50 \%$, PNE were removed. For final implantation, a tined quadripolar lead was inserted into the same sacral foramen and evaluated under radiological and electrophysiological monitoring as with the PNE. The electrode was then leaded subcutaneously and connected with an implantable pulse generator (IPG, Medtronic, Interstim 3625) according to the manufacturer's recommendations. The IPG was implanted and fixed subcutaneously in the gluteal area, and the wound was closed in two-layer suture. Stimulation was started $12 \mathrm{~h}$ after intervention with a program configuration according to patient's sensory response. Wound scaring, local pain, and therapy success were controlled 2 and 6 weeks after the procedure.

\section{Statistics}

Since most variables showed skewed distributions, nonparametric tests were used for statistical comparison. Continuous variables are displayed as median (minimummaximum), and categorical variables are displayed as count (percentage). ASA is displayed as mean (minimummaximum) to allow for a finer graduation. The Mann-Whitney $\mathrm{U}$ test was used to compare two independent groups. For dependent variables, the Wilcoxon test was used. The chisquare test was used for group comparisons of categorical variables. The level of significance was 0.05 (two-sided) for each statistical testing. The statistical analysis was performed with SPSS Statistics Software 25.0 (IBM, Armonk, NY, USA).

\section{Ethics}

The Medical Ethical Committee of Charité Universitätsmedizin Berlin (EA1/289/20) approved the study protocol.

\section{Results}

\section{Demographics}

A total of 23 patients underwent SNS implantation for fecal incontinence or high stool frequency (Table 1). Sixty-nine percent of these patients $(n=16)$ were successfully treated 
Table 1 Demographics

\begin{tabular}{ll}
\hline & $\mathrm{N}=23$ \\
\hline Age, years & $53(27-69)$ \\
Sex, male & $15(65)$ \\
BMI, kg/m² & $23.5(18.8-38.9)$ \\
Multi-stage procedure & \\
Two-stage & $16(74)$ \\
Three-stage & $7(26)$ \\
IPAA & \\
Hand-sewn & $21(93)$ \\
Stapled & $2(7)$ \\
Time to SNS, years & $6(0.5-14.5)$ \\
Successful SNS & $16(69)$ \\
Follow-up, years (95\% CI) & $6.5(4.2-8.8)$ \\
\hline
\end{tabular}

$B M I$ body mass index, IPAA ileal pouch anal anastomosis, SNS sacral nerve stimulation, Time to SNS = time between IPAA and SNS. Median (min-max) for continuous variables, count (percent) for categorical variables

with SNS. In 7 patients $(31 \%)$, the test electrode had to be removed as the improvement was below 50\%. Median follow-up time was 6.5 years. Two patients were lost to follow-up.

\section{Possible factors influencing the success of SNS}

Of our patients, $74 \%$ had a two-stage procedure, and $26 \%$ had a three-stage procedure (Table 2). The choice of procedure had no significant influence on the success rate $(\mathrm{p}=0.618)$. Patients with frustrated SNS implantation had a significantly higher BMI in contrast to successful SNS (30.2 kg/m ${ }^{2}$ vs. $\left.22.8 \mathrm{~kg} / \mathrm{m}^{2} ; \mathrm{p}=0.008\right)$. In addition, we examined the type of IPAA (hand-sewn vs. stapled), whereby the majority of IPAAs $(91 \%)$ were hand-sewn, so that no statistical differences could be found. The median time from IPAA to SNS was 6.7 years for successful SNS and 2.2 years for non-successful SNS, but with no significant difference $(\mathrm{p}=624)$.

\section{Successful SNS implantation}

Fecal incontinence at night significantly improved after SNS implantation (Table 3). However, SNS did not affect stool frequency in general. Table 4 shows a significant improvement in the St. Marks incontinence score from 19 to 2 in patients with successful SNS implantation $(\mathrm{p}=0.012)$. The amount of continence supporting tools (biofeedback, pelvic floor training) and antidiarrheal agents did not change after SNS implantation.

Table 5 shows all 16 successful SNS implantations. Median follow-up in this patient group was 5.1 years (1.7-8.4). One patient was lost to follow-up. Median time from IPAA to SNS was 6.7 years (1.2-14.4). Despite missing data due to lack of documentation, $\mathrm{St}$. Marks incontinence score and nocturnal incontinence at night were better for most patients.

\section{Failed SNS implantation}

Table 6 shows demographics and results of all seven failed SNS implantations. After a control period of at least 3 months, test electrodes were removed when the procedure was not successful. The pouch was removed in three patients due to severe pouchitis, persistent incontinence, or severe anal pain. Two patients received an ostomy again because of persistent incontinence. Two patients were lost to follow-up.
Table 2 Possible factors influencing the success of SNS

\begin{tabular}{lllll}
\hline & $\begin{array}{l}\text { Success } \\
\mathrm{N}=16\end{array}$ & $\begin{array}{l}\text { No success } \\
\mathrm{N}=7\end{array}$ & Missing & P-value \\
\hline Age, years & $53(27-69)$ & $53(30-63)$ & - & 0.769 \\
Sex, male & $11(69)$ & $4(57)$ & - & 0.467 \\
BMI, kg/m & $22.8(18.8-27.4)$ & $30.2(24.9-38,39)$ & 9 & 0.008 \\
Multi-stage procedure & & & - & 0.681 \\
Two-stage & $12(75)$ & $5(71)$ & & \\
Three-stage & $4(25)$ & $2(29)$ & - & 0.526 \\
IPAA, hand-sewn & $15(94)$ & $6(86)$ & & \\
IPAA, stapled & $1(6)$ & $1(14)$ & - & 0.624 \\
Time to SNS, years & $6.7(1.2-14.4)$ & $2.2(0.5-14.5)$ & \\
\hline
\end{tabular}

$B M I$ body mass index, IPAA ileal pouch anal anastomosis, SNS sacral nerve stimulation, Time to SNS = time between IPAA and SNS. Median (min-max) for continuous variables, count (percent) for categorical variables 
Table 3 Results after 16 successful SNS implantations

\begin{tabular}{|c|c|c|c|c|c|}
\hline & $\begin{array}{l}\text { Before SNS } \\
\mathrm{N}=16\end{array}$ & Missing & $\begin{array}{l}\text { After SNS } \\
\mathrm{N}=16\end{array}$ & Missing & $P$ value \\
\hline Stool frequency & $9(8-18)$ & $11(68)$ & $6(3-6)$ & $13(81)$ & 0.102 \\
\hline Nocturnal fecal incontinence & $6(38)$ & $10(62)$ & $5(31)$ & $11(68)$ & 0.025 \\
\hline St. Marks incontinence score & $19(4-24)$ & $6(37)$ & $4(0-18)$ & $3(19)$ & 0.012 \\
\hline DRESS Score & $2(0-4)$ & $8(50)$ & $3(2-4)$ & $2(13)$ & 0.414 \\
\hline \multicolumn{6}{|l|}{ Continence supporting tools } \\
\hline Biofeedback & $5(31)$ & $5(31)$ & 0 & $1(6)$ & 0.739 \\
\hline Pelvic floor training & $3(19)$ & $5(31)$ & 0 & $1(6)$ & 0.257 \\
\hline \multicolumn{6}{|l|}{ Antidiarrheal agents } \\
\hline Loperamide & $9(56)$ & $5(31)$ & $10(63)$ & $1(6)$ & 0.083 \\
\hline Tincture of opium & $2(13)$ & $5(31)$ & $1(6)$ & $1(6)$ & 0.206 \\
\hline Apple fruit extract & $3(19)$ & $5(31)$ & $1(6)$ & $1(6)$ & 0.366 \\
\hline
\end{tabular}

St. Marks incontinence score $(\min .=0, \max .=24)$. DRESS Score (= digital rectal examination scoring system; $\min .=0$, $\max .=5)$. Median $(\min -\max )$ for continuous variables, count (percent) for categorical variables

\section{Discussion}

The aim of our study was to evaluate the feasibility and the benefit of sacral nerve stimulation (SNS) in the treatment of fecal incontinence in patients with J-pouch reconstruction and ileal pouch-anal anastomosis (IPAA).

Our study shows the feasibility of SNS in IPAA patients by improving fecal incontinence (as measured by the St. Marks incontinence score) in more than two-thirds of patients with fecal incontinence or high stool frequency. The St. Marks incontinence or Vaizey score was used as a rating system for the assessment of the severity of fecal incontinence [19]. Our results showed a significant improvement after SNS implantation from 19 to 4 in the St. Marks incontinence score. There is some evidence that shows a positive correlation between St. Marks incontinence score and quality of life [20,21]. With decreasing severity of the St. Marks incontinence score, the quality of life measured with the Manchester Health Questionnaire (MHQ) was improved [21]. Due to this positive correlation, indirect conclusions can also be drawn about a better quality of life observed in our patient cohort after successful SNS implantation. In our study, we were able to demonstrate an improvement in nighttime incontinence after SNS. Although some data were missing for the evaluation,

Table 4 Differences in incontinence before and after SNS (St. Marks incontinence score)

\begin{tabular}{lrrr}
\hline & Before SNS & After SNS & P-value \\
\hline Successful SNS & $19(4-22)$ & $2(0-10)$ & 0.012 \\
Non-successful SNS & $20(12-24)$ & $20(0-24)$ & 0.317 \\
\hline
\end{tabular}

St. Marks incontinence score $(\min .=0, \max .=24) S N S$ sacral nerve stimulation, Time to SNS = time between IPAA and SNS this may indicate a possible improvement in quality of life after SNS for these patients.

In the analysis of possible factors influencing the success of SNS, a significantly higher BMI of $30.2 \mathrm{~kg} / \mathrm{m}^{2}$ (24.9-38.9) was found for non-successful SNS. However, the statistical significance of BMI on success after SNS must be taken with caution in view of the missing data. The data lack is mainly due to the conversion of the patient recording system from analog to digital over the years. However, it is consistent with the literature that there are more perioperative problems with IPAA in obese patients $[22,23]$.

Increased stool frequency is another reported factor that negatively impacts quality of life [9]. However, overall stool frequency was not affected by SNS implantation in this analysis. This is reflected in previous work describing low daytime fecal incontinence of 1 to $25 \%$ in contrast to nighttime incontinence of 8 to $49 \%$ [2-8].

In seven patients, the therapy had to be discontinued after the test phase and the electrodes removed because the SNS implantation was not successful. In some of these patients, a new stoma or even a pouch explantation had to be performed. Postoperative pouchitis or fistulas could be a cause of reduced pouch function. As described in the literature, chronic pouchitis, fistulas, leakage, or conversion to a diagnosis of Crohn's disease pose a clear risk for failure of the J-pouch and IPAA [24, 25]. However, some patients had persistent incontinence for no apparent reason. Further investigations seem necessary to clarify the causes of SNS failure.

A limitation of this study was the partially incomplete data collection. On the one hand, this is due to the very long study period of 20 years with a certain loss of data due to the conversion of the documentation from analog to digital. 
Table 5 Demographics and results of all 16 successful SNS implantation

\begin{tabular}{|c|c|c|c|c|c|c|c|}
\hline & Age/sex & $\begin{array}{l}\text { Time to SNS, } \\
\text { years }\end{array}$ & $\begin{array}{l}\text { Stool frequency } \\
\text { before/after SNS }\end{array}$ & $\begin{array}{l}\text { Nightly incontinence } \\
\text { before/after SNS }\end{array}$ & $\begin{array}{l}\text { DRESS } \\
\text { before/after } \\
\text { SNS }\end{array}$ & $\begin{array}{l}\text { St. Marks score } \\
\text { before/after SNS }\end{array}$ & $\begin{array}{l}\text { Follow-up, } \\
\text { years }\end{array}$ \\
\hline Patient 1 & 49/male & 7.6 & $-/-$ & $-/-$ & $3 / 2$ & $-/-$ & 0.1 \\
\hline Patient 2 & $65 /$ female & 6 & $-/-$ & $-/-$ & $-/ 3$ & $-/ 10$ & 10.7 \\
\hline Patient 3 & 50/male & 5 & $-/-$ & $-/-$ & $-/ 3$ & $-/ 18$ & 7.8 \\
\hline Patient 4 & $54 /$ male & 1.8 & $-/-$ & $-/-$ & $-/ 3$ & $-/ 18$ & 6.8 \\
\hline Patient 5 & $52 /$ male & 8.9 & $-/-$ & $-/-$ & $-/ 3$ & $-/ 0$ & 8.5 \\
\hline Patient 6 & $51 /$ male & 13.1 & $-/-$ & $-/-$ & $-/ 3$ & $-/ 4$ & 6.5 \\
\hline Patient 7 & 44/female & 5.6 & $-/-$ & $-/-$ & $-/ 3$ & $20 / 4$ & 3.3 \\
\hline Patient 8 & 59/male & 2 & 8/- & $1 / 0$ & $3 / 3$ & $24 /-$ & 2.3 \\
\hline Patient 9 & $42 /$ male & 12.8 & $-/-$ & $-/-$ & $4 / 4$ & $14 / 2$ & 5.1 \\
\hline Patient 10 & $62 /$ male & 14.4 & $-/-$ & $-/-$ & $3 / 2$ & $4 / 2$ & 5.1 \\
\hline Patient 11 & 27/female & 1.3 & $-/-$ & $-/-$ & $2 / 3$ & $12 / 2$ & 2.9 \\
\hline Patient 12 & $54 /$ female & 7.9 & $18 / 6$ & $1 / 0$ & $-/-$ & $20 / 0$ & 3.4 \\
\hline Patient 13 & 59/male & 7.5 & $11 / 6$ & $1 / 0$ & $2 / 2$ & $20 / 4$ & 0.3 \\
\hline Patient 14 & $69 /$ male & 13.8 & $8 / 3$ & $1 / 0$ & $2 / 2$ & $18 / 0$ & 4.0 \\
\hline Patient 15 & 44/male & 2.3 & $9 /-$ & $1 / 0$ & $-/-$ & $22 / 10$ & 8.7 \\
\hline Patient 16 & 54/female & 1.2 & $-/-$ & $1 /-$ & $0 / 2$ & $10 /-$ & 0 \\
\hline
\end{tabular}

Time to SNS time from IPAA to SNS. DRESS Score (=digital rectal examination scoring system; min. $=0$, max. $=5$ ) IPAA ileal pouch anal anastomosis, SNS sacral nerve stimulation

On the other hand, the follow-up data are missing because they were either collected in the patients' hometowns or not at all. A retrospective survey might have yielded more results. Our results on stool frequency and nocturnal incontinence must therefore be interpreted cautiously, as the number of missing values was quite high.
However, the strength of our work lies in the relatively large number of patients and the long follow-up period with an average of 6 years. As there are only single case reports and small studies in the literature so far, it is now possible to make more comprehensive statements about the success of SNS use for fecal incontinence after IPAA.

Table 6 Demographics and results of all 7 failed SNS implantation

\begin{tabular}{|c|c|c|c|c|c|c|c|c|}
\hline & Age/sex & $\begin{array}{l}\text { Time to SNS, } \\
\text { years }\end{array}$ & $\begin{array}{l}\text { Stool frequency } \\
\text { before/after } \\
\text { SNS }\end{array}$ & $\begin{array}{l}\text { Nightly inconti- } \\
\text { nence before/after } \\
\text { SNS }\end{array}$ & $\begin{array}{l}\text { DRESS } \\
\text { before } \\
\text { /after } \\
\text { SNS }\end{array}$ & $\begin{array}{l}\text { St. Marks score } \\
\text { before/after SNS }\end{array}$ & $\begin{array}{l}\text { Follow-up, } \\
\text { years }\end{array}$ & Clinical course \\
\hline Patient 1 & 30/female & 1.4 & $9 / 9$ & $1 / 1$ & $2 / 2$ & $20 / 20$ & 0.5 & $\begin{array}{l}\text { Anal pain, stenotic } \\
\text { IPAA, pouch explan- } \\
\text { tation }\end{array}$ \\
\hline Patient 2 & $30 /$ male & 0.5 & - & $-/-$ & $2 / 2$ & $25 / 25$ & 0.01 & $\begin{array}{l}\text { Severe pouchitis } \\
\text { resulted in Pouch } \\
\text { explantation }\end{array}$ \\
\hline Patient 3 & 63/male & 1.1 & $12 / 10$ & $-/-$ & $-/-$ & $12 / 0$ & 7.5 & $\begin{array}{l}\text { Persisting incontinence, } \\
\text { new stoma }\end{array}$ \\
\hline Patient 4 & 57/male & 9.4 & $8 /-$ & $1 /-$ & $-/-$ & $8 / 25$ & 0 & Patient lost to follow-up \\
\hline Patient 5 & $53 /$ male & 13.3 & $14 / 14$ & $1 / 1$ & $1 / 1$ & $20 / 20$ & 10.9 & $\begin{array}{l}\text { Persisting incontinence, } \\
\text { Pouch explantation }\end{array}$ \\
\hline Patient 6 & $50 /$ female & 14.5 & $20 / 20$ & $1 / 1$ & $1 / 1$ & $24 / 24$ & 0.05 & Patient lost to follow-up \\
\hline Patient 7 & 46/female & 2.2 & $8 / 8$ & $1 / 1$ & $0 / 0$ & $16 / 16$ & 0.2 & $\begin{array}{l}\text { Persisting incontinence, } \\
\text { new stoma }\end{array}$ \\
\hline
\end{tabular}

Time to SNS = time from IPAA to SNS. DRESS Score (=digital rectal examination scoring system; min. $=0$, max. $=5) I P A A$ ileal pouch anal anastomosis, SNS sacral nerve stimulation 


\section{Conclusions}

SNS implantation for the treatment of fecal incontinence and high stool frequency in patients with J-pouch and ulcerative colitis shows good results. SNS appears to be a good therapy option for these patients and should be considered at an early stage and may offer an alternative to J-pouch removement or permanent stoma application.

Author contribution Claudia Seifarth and Nadia Slavova contributed equally to this work. Claudia Seifarth, Nadia Slavova, and Benjamin Weixler contributed to the study conception and design. Claudia Seifarth, Nadia Slavova, and Claudius Degro collected the patients' data, analyzed, and interpreted the experimental data. Statistical analysis was performed by Claudia Seifarth and Kai Lehmann. The first draft of the manuscript was written by Claudia Seifarth and Nadia Slavova, and all authors commented on previous versions of the manuscript. All authors read and approved the final manuscript.

Funding Open Access funding enabled and organized by Projekt DEAL.

Availability of data and material The data that support the findings of this study are available from the corresponding author upon reasonable request.

\section{Declarations}

Ethics approval The Ethics committee of the Charité Universitätsmedizin Berlin (EA1/289/20) approved the study protocol.

Conflict of interest The authors declare no competing interests.

Open Access This article is licensed under a Creative Commons Attribution 4.0 International License, which permits use, sharing, adaptation, distribution and reproduction in any medium or format, as long as you give appropriate credit to the original author(s) and the source, provide a link to the Creative Commons licence, and indicate if changes were made. The images or other third party material in this article are included in the article's Creative Commons licence, unless indicated otherwise in a credit line to the material. If material is not included in the article's Creative Commons licence and your intended use is not permitted by statutory regulation or exceeds the permitted use, you will need to obtain permission directly from the copyright holder. To view a copy of this licence, visit http://creativecommons.org/licenses/by/4.0/.

\section{References}

1. Lichtenstein GR, Cohen R, Yamashita B, Diamond RH (2006) Quality of life after proctocolectomy with ileoanal anastomosis for patients with ulcerative colitis. J Clin Gastroenterol 40:669-677. https://doi.org/10.1097/00004836-200609000-00002

2. Kong E, Nikolaou S, Qiu S et al (2018) A systematic review of sacral nerve stimulation for faecal incontinence following ileal pouch anal anastomosis. Updates Surg 70:1-5. https://doi.org/10. 1007/s13304-017-0496-y

3. Tekkis PP, Lovegrove RE, Tilney HS et al (2010) Long-term failure and function after restorative proctocolectomy - a multi-centre study of patients from the UK National Ileal Pouch Registry. Colorectal Dis 12:433-441. https://doi.org/10.1111/j.1463-1318.2009.01816.x

4. Michelassi F, Lee J, Rubin M et al (2003) Long-term functional results after ileal pouch anal restorative proctocolectomy for ulcerative colitis: a prospective observational study. Ann Surg 238:433-441; discussion 442-445. https://doi.org/10.1097/01.sla. 0000086658.60555.ea

5. Delaney CP, Remzi FH, Gramlich T et al (2002) Equivalent function, quality of life and pouch survival rates after ileal pouch-anal anastomosis for indeterminate and ulcerative colitis. Ann Surg 236:43-48. https://doi.org/10.1097/00000658-200207000-00008

6. Carcamo L, Miranda P, Zúñiga A et al (2020) Ileal pouch-anal anastomosis in ulcerative colitis: outcomes, functional results, and quality of life in patients with more than 10-year followup. Int J Colorectal Dis 35:747-753. https://doi.org/10.1007/ s00384-020-03529-7

7. Meagher AP, Farouk R, Dozois RR et al (1998) J ileal pouch-anal anastomosis for chronic ulcerative colitis: complications and long-term outcome in 1310 patients. Br J Surg 85:800-803. https://doi.org/10.1046/j.1365-2168.1998.00689.x

8. Abdalla M, Norblad R, Olsson M et al (2020) Anorectal function after ileo-rectal anastomosis is better than pelvic pouch in selected ulcerative colitis patients. Dig Dis Sci 65:250-259. https://doi.org/10.1007/s10620-019-05757-6

9. Leowardi C, Hinz U, Tariverdian M et al (2010) Long-term outcome 10 years or more after restorative proctocolectomy and ileal pouch-anal anastomosis in patients with ulcerative colitis. Langenbecks Arch Surg 395:49-56. https://doi.org/10.1007/ s00423-009-0479-7

10. Tomita R, Sugito K, Sakurai K et al (2014) Sacral nerve function in child patients after ileal J-pouch-anal anastomosis for ulcerative colitis. Int Surg 99:506-511. https://doi.org/10.9738/ INTSURG-D-13-00043.1

11. Matzel KE (2011) Sacral nerve stimulation for faecal incontinence: its role in the treatment algorithm. Colorectal Dis 13(Suppl 2):10 14. https://doi.org/10.1111/j.1463-1318.2010.02519.x

12. Thin NN, Horrocks EJ, Hotouras A et al (2013) Systematic review of the clinical effectiveness of neuromodulation in the treatment of faecal incontinence. Br J Surg 100:1430-1447. https://doi.org/ 10.1002/bjs.9226

13. van Wunnik BP, Govaert B, Leong R et al (2011) Patient experience and satisfaction with sacral neuromodulation: results of a single-center sample survey. Dis Colon Rectum 54:95-100. https://doi.org/10.1007/DCR.0b013e3181f46810

14. Leroi AM, Damon H, Faucheron JL et al (2009) Sacral nerve stimulation in faecal incontinence: position statement based on a collective experience. Colorectal Dis 11:572-583. https://doi.org/ 10.1111/j.1463-1318.2009.01914.x

15. Maeda Y, O'Connell PR, Lehur P-A et al (2015) Sacral nerve stimulation for faecal incontinence and constipation: a European consensus statement. Colorectal Dis 17:O74-87. https://doi.org/10.1111/ codi. 12905

16. Lebas A, Rogosnitzky M, Chater C et al (2014) Efficacy of sacral nerve stimulation for poor functional results of J-pouch ileoanal anastomosis. Tech Coloproctol 18:355-360. https://doi.org/10. 1007/s10151-013-1058-Z

17. Meurette G, Wong M, Paye F et al (2011) Sacral nerve stimulation for the treatment of faecal incontinence after ileal pouch anal anastomosis. Colorectal Dis 13:e182-e183. https://doi.org/10.1111/j. 1463-1318.2010.02352.x

18. Mege D, Meurette G, Vitton V et al (2017) Sacral nerve stimulation can alleviate symptoms of bowel dysfunction after colorectal resections. Colorectal Dis 19:756-763. https://doi.org/10.1111/ codi. 13624 
19. Vaizey CJ, Carapeti E, Cahill JA, Kamm MA (1999) Prospective comparison of faecal incontinence grading systems. Gut 44:7780. https://doi.org/10.1136/gut.44.1.77

20. Paka C, Atan IK, Dietz HP (2016) The bother of anal incontinence and St. Mark's Incontinence Score Tech Coloproctol 20:123-128. https://doi.org/10.1007/s10151-015-1397-z

21. Roos A-M, Sultan AH, Thakar R (2009) St. Mark's incontinence score for assessment of anal incontinence following obstetric anal sphincter injuries (OASIS). Int Urogynecol J Pelvic Floor Dysfunct 20:407-410. https://doi.org/10.1007/s00192-008-0784-7

22. Poh KS, Qureshi S, Hong YK et al (2020) Multivariate prediction of intraoperative abandonment of ileal pouch anal anastomosis. Dis Colon Rectum 63:639-645. https://doi.org/10.1097/DCR. 0000000000001617
23. Traynor MD, McKenna NP, Habermann EB et al (2019) Utilization of maneuvers to increase mesenteric length employed in children undergoing ileal pouch-anal anastomosis. J Laparoendosc Adv Surg Tech A 29:1285-1291. https://doi.org/10.1089/lap.2019.0124

24. Helavirta I, Lehto K, Huhtala $\mathrm{H}$ et al (2020) Pouch failures following restorative proctocolectomy in ulcerative colitis. Int J Colorectal Dis 35:2027-2033. https://doi.org/10.1007/s00384-020-03680-1

25. Uchino M, Ikeuchi H, Sugita A et al (2018) Pouch functional outcomes after restorative proctocolectomy with ileal-pouch reconstruction in patients with ulcerative colitis: Japanese multi-center nationwide cohort study. J Gastroenterol 53:642-651. https://doi. org/10.1007/s00535-017-1389-z 